\title{
Basal and regulatory promoter studies of the AKR1C3 gene in relation to prostate cancer
}

\author{
Jenny J. Schulze, Helena Karypidis and Lena Ekström*
}

Department of Laboratory Medicine, Karolinska Institutet, Stockholm, Sweden

Edited by:

Yi Jin, University of Pennsylvania, USA

Reviewed by:

Jonine D. Figueroa, National Cancer Institute, USA

Kar-Ming Fung, University of

Oklahoma Health Sciences Center,

USA

\section{*Correspondence:}

Lena Ekström, Clinical Pharmacology

C1:68, Karolinska University Hospital,

14186 Stockholm, Sweden.

e-mail: lena.ekstrom@ki.se

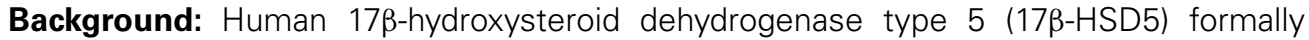
known as aldo-keto reductase 1C3 (AKR1C3) play a major role in the formation and metabolism of androgens. The enzyme is highly expressed in the prostate gland and previous studies indicate that genetic variation in the AKR1C3 gene may influence the prostate volume and risk of prostate cancer. Aim: Here we aimed to further study the genetic regulation of $\mathrm{AKR} 1 \mathrm{C} 3$ and its putative role in prostate cancer. Experiments: A previously identified promoter polymorphism ( $\mathrm{A}>\mathrm{G}$, rs3763676) localized at -138 from the translational start site were studied in relation to prostate cancer in a Swedish population based case-control study including 176 patients diagnosed with prostate cancer and 161 controls. Moreover, we have studied the basal and androgen induced promoter activity of the AKR1C3 gene. Expression studies with AKR1C3 promoter reporter constructs were performed in HepG2 and DSL2 cells. Results: We found that carriers of the promoter A-allele had a borderline significant decreased risk of prostate cancer $(\mathrm{OR}=0.59 ; 95 \% \mathrm{Cl}=0.32-1.08)$. We also show that dihydrotestosterone (DHT) induced the promoter activity of the A-allele 2.2-fold $(p=0.048)$. Sp3 seem to play an important role in regulating the transcription activity of AKR1 C3 and site-directed mutagenesis of a GC-box 78 base-pair upstream the ATG-site significantly inhibited the basal AKR1C3 promoter activity by $70 \%$. Conclusion: These results further supports previous findings that the $A>G$ promoter polymorphism may be functional and that AKR1C3 plays a critical role in prostate carcinogenesis. Our findings also show that the members of $\mathrm{Sp}$ family of transcription factors are important for the constitutive expression of AKR1C3 gene.

Keywords: AKR1C3, 17BHSD5, prostate cancer, DHT, polymorphism, gene regulation

\section{INTRODUCTION}

Human $17 \beta$-HSD type 5 belongs to the aldo-keto reductase (AKR) superfamily (Jez et al., 1997) and is formally known as AKR1C3. It is a promiscuous enzyme that participates in the biosynthesis and metabolism of a variety of substrates including androgens, estrogens (Penning et al., 2000), prostaglandins (Matsuura et al., 1998), and polycyclic aromatic hydrocarbons (PAH; Palackal et al., 2002). AKR1C3 is widely expressed in human tissues and is predominant in the prostate and mammary gland (Penning et al., 2000).

The 17-keto reductase activity of AKR1C3 reduces the weak androgen $\Delta^{4}$-androstenedione (4-dione) to testosterone. The combined $3 \alpha / 3 \beta$ activity of the enzyme (Steckelbroeck et al., 2004) partly inactivates $5 \alpha$-dihydrotestosterone (DHT) to the weak androgens $3 \alpha$-androstanediol ( $3 \alpha$-Adiol) and $3 \beta$-androstanediol

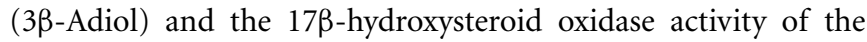
enzyme oxidizes $3 \alpha$-Adiol to androsterone instead of back to DHT (Penning et al., 2000).

The prostate gland is generally considered an important site of DHT formation and inactivation (Thigpen et al., 1993). DHT stimulates the proliferation of the prostate and AKR1C3 has been shown to be up-regulated in localized and advanced prostate adenocarcinoma (Nakamura et al., 2005; Fung et al., 2006; Stanbrough et al., 2006).
Previously an $A>G$ polymorphism in the promoter region (rs3763676) at nucleotide position -138 from the translation start site was identified (Qin et al., 2006). The G-allele has been associated with lower promoter activity in human liver (HepG2), lung (A549), and prostate (LNCaP) cells (Jakobsson et al., 2007) and higher promoter activity in rat theca cells (Qin et al., 2006). The allele frequency of this SNP was shown to be significantly increased in patients with polycystic ovary syndrome (PCOS; Qin et al., 2006) and increased risk for bladder cancer (Figueroa et al., 2008) whereas its involvement in prostate cancer has not been studied.

Previous studies of the AKR1C3 promoter have shown that a 169-bp region $(-104$ to +65$)$ is capable of directing transcriptional activity (Ciaccio et al., 1996). This $5^{\prime}$-flanking region contains a CTT-repeat element, two GC-boxes, and a reverse CCAAT-box. The GC- and CCAAT-boxes generally work as promoter signals in many eukaryotic cells. There is one study showing the Sp family of transcription factors play an important role in regulating constitutive expression of the AKR1C3 (Qin and Rosenfield, 2005).

The overall aim of this study is to increase the understanding on how AKR1C3 is genetically regulated and its putative role in prostate cancer. More specifically the aims of this study are to investigate (1) the influence of the CCAAT and the GC-elements 
on the basal expression of the human AKR1C3 gene in HepG2 cells, (2) investigate if DHT affect the transcriptional activity of $\mathrm{AKR} 1 \mathrm{C} 3$ in relation to the promoter $\mathrm{A}>\mathrm{G}$ polymorphism, and (3) the allele frequency of this promoter SNP in relation to risk for prostate cancer in a Swedish population.

\section{MATERIALS AND METHODS SITE-DIRECTED MUTAGENESIS}

Mutations in the CCAAT and GC-boxes were introduced using the pGLAKR1C3prom construct (Jakobsson et al., 2007) as template and the antisense primers ( $5^{\prime}$-gatggttaacatctggcatgtag- $\left.{ }^{\prime} 3\right)$ and $\left(5^{\prime}\right.$ gaaaccctcccaacaccctg- ${ }^{\prime} 3$ ) including the mutations together with a sense primer $\left(5^{\prime}\right.$-ggttgctatttgttctacaaa- $\left.{ }^{\prime} 3\right)$. The PCRs were performed in $2 \mathrm{mM} \mathrm{MgCl}_{2}, 0.15 \mathrm{mM}$ dNTP, $0.3 \mu \mathrm{l}$ Taq Polymerase, $20 \mathrm{pmol}$ of each primer, $100 \mathrm{ng}$ of template, and were carried out in 30 cycles, each involving denaturing at $94^{\circ}, 45 \mathrm{~s}$, annealing at $53^{\circ}, 45 \mathrm{~s}$, elongation at $72^{\circ}, 1 \mathrm{~min}$, followed by $7 \mathrm{~min}$ elongation. The PCR products were gel-purified (Qiagen) and used as a mega primer together with an antisense primer $\left(5^{\prime}\right.$-cattcctgtcacttgtctg'3) in a second PCR. The product was subcloned into a TA-vector (Invitrogen) and cleaved with the restriction enzymes, XhoI and Kpn1 (New England BioLabs), gel-purified, and subcloned into similar digested pGL3 Basic vectors (Promega). All the mutations were verified by sequence analysis.

\section{CELL CULTURE}

Human hepatoma HepG2 cells were maintained at $37^{\circ} \mathrm{C}$ in $5 \%$ $\mathrm{CO}_{2}$ in $\mathrm{MEM}, 10 \%$ bovine serum, $2 \mathrm{mM}$ glutamine, $1 \mathrm{mM}$ sodium pyruvate, non-essential amino acids, $100 \mathrm{U}$ penicillin, and $100 \mu \mathrm{g}$ streptomycin/ml.

Drosophila DSL2 cells were maintained at room temperature in Schneider's Medium, 10\% bovine serum, $2 \mathrm{mM}$ glutamine, $100 \mathrm{U}$ penicillin, and $100 \mu \mathrm{g}$ streptomycin $/ \mathrm{ml}$.

All cell culture media and their ingredients were obtained from GIBCO/BRL (Gaithersburg, MD, USA).

\section{TRANSFECTION ASSAY}

HepG2 cells were plated in $35 \mathrm{~mm} 6$-well plates at $2 \times 10^{5} /$ well and incubated overnight. The cells were transfected using $15 \mu \mathrm{l}$ Lipofectin (Life Technology), $2.5 \mu \mathrm{g}$ pGLAKR1C3 Basic plasmid, and $2.5 \mu \mathrm{g} \beta$-gal control vector (Promega). Cells were incubated for $5 \mathrm{~h}$ at $37^{\circ} \mathrm{C}$, the transfection solution was then replaced with fresh media. DSL2 cells were plated in $36 \mathrm{~mm}$ 6-well plates at $2 \times 10^{6}$ cells/well at the day of transfection. Two micrograms of pGLBasicAKR1C3 plasmid, $2.5 \mu \mathrm{g} \beta$-gal control vector (Promega), 0.5-1.5 $\mu$ g of Sp1, and/or Sp3 expression vectors (pPACSp 1 and/or pPACSp3 kindly provided by Dr. Ahmed Zaid) and $10 \mu$ l Superfect (Qiagen) were used in each transfection reaction. Cells were incubated for $3 \mathrm{~h}$ at room temperature, the transfection solution were then replaced with fresh media. Cells were harvested $48 \mathrm{~h}$ after transfection and luciferase activity was determined using luciferase assay reagent (Promega). $\beta$ gal activity was measured using ortho-nitrophenyl $\beta$-D-galactopyranoside (Sigma) as a substrate. All values were corrected for endogenous galactosidase activity. The luciferase values were divided by the $\beta$ gal value in order to correct for transfection efficiency.

\section{REAL-TIME PCR}

Total RNA was extracted from DHT exposed HepG2 cells with Trizol reagent (Invitrogen) according to the manufacturers manual. $1 \mu \mathrm{g}$ RNA was reverse transcribed using First-strand cDNA Synthesis Kit (Amersham) with a random hexamer oligonucleotide. Real-time PCR was performed using $1 \mu \mathrm{lcDNA}, 10$ pmol AKR1C3 specific primers (Bogason et al., 2011), SYBR Green (Applied Biosystems), and quantified in an ABI Prism 700. Dilutions of a plasmid containing AKR1C3 cDNA (19T7-AKR1C3Glu77; Jakobsson et al., 2007) was used to construct a standard curve. For normalization of cDNA input in each PCR, 18S mRNA was used as an endogenous control.

\section{HUMAN STUDY}

In another part of the study a population based case-control study of 337 Caucasians living in the county of Örebro in Sweden were investigated. The cases were 176 patients, age 51-79 years, with prostate cancer, who were recruited consecutively between May 1994 and February 1996. In all, 81\% agreed to participate. The controls were men, who were randomly selected every 3 months from the county population register and frequency matched for age. They were asked to participate by mail and 161 individuals agreed to participate, giving a response rate of $79 \%$. Further description of the study population has been already published since this study population has been utilized in the evaluation of other polymorphisms involved in the androgen metabolism (Wadelius et al., 1999; Söderström et al., 2002). The Ethics Committee of the Regional Hospital of Örebro/Uppsala University, Sweden approved the study and all patients gave informed consent to participate. Genotyping of the $\mathrm{A}>\mathrm{G}$ promoter polymorphism was performed as described previously (Jakobsson et al., 2007).

\section{DATA ANALYSIS}

Data of promoter activity and real-time PCR are expressed as mean \pm SD Significance was assessed using two-tail Student's $t$ test using GraphPad Prism software v4.03 (San Diego, CA, USA). Genotype associations were assessed with binary logistic regression using Minitab statistical software package (v 12.1, Minitab Inc., State College, PA, USA). ORs were used as an approximation of relative risk, using $95 \%$ confidence intervals.

\section{RESULTS \\ FUNCTIONAL ANALYSIS OF HUMAN AKR1C3 BASAL PROMOTER ACTIVITY}

Transfection assay with wildtype and mutant reporter constructs were performed in HepG2 cells to study the effect of the CCAATand GC-box mutations on luciferase activity. Mutation of the CCAAT-box did not inhibit the promoter activity in HepG2, instead a borderline $(p=0.06)$ significant $50 \%$ increase was observed (Figure 1).

Transfections with the reporter construct including a mutated GC-box indicate that the promoter activity decreased significant (70\%, $p<0.05)$ in HepG2 cells (Figure 1). These results indicate that the GC-box is important for directing and activating the transcription of the AKR1C3 gene in HepG2 cells.

Transfections with the wildtype promoter construct in DSL2 cells show that when increasing concentrations of Sp3 $(0.5,1.0$, and 


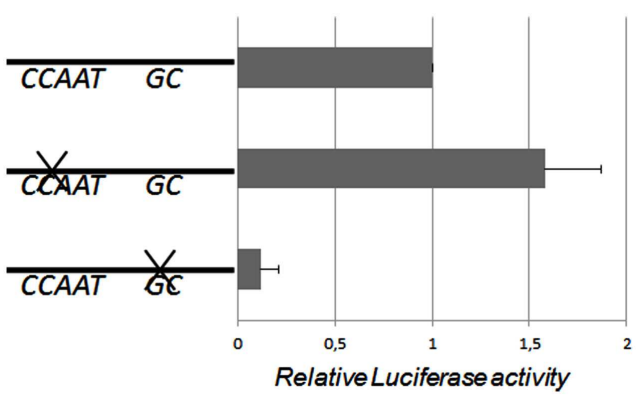

FIGURE 1 | Human AKR1C3 promoter fragment was subcloned into the pGL3 Basic vector and the CCAAT- and GC-elements were mutated and transiently transfected into HepG2 cells. The bar graph represents mean \pm SD from at least three experiments. The luciferase expression was normalized to the transfection efficiency by $\beta$-galactosidase expression. When the CCAAT-box was mutated there was a borderline significant $50 \%$ increase in the relative luciferase activity. When the GC-box was mutated the luciferase activity significantly decreased indicating that the GC-box is required for the basal transcription of the AKR1C3 gene in HepG2 cells.

$1.5 \mu \mathrm{g}$ ) were added to the cells, the promoter activity increased 1.5 times, whereas no activation of the basal activity of shown when increasing concentrations $(0.5,1.0$, and $1.5 \mu \mathrm{g})$ of $\mathrm{Sp} 1$ were added (Figure 2A).

When Sp3 was added at $1 \mu \mathrm{g}$ the addition of Sp1 $(1 \mu \mathrm{g})$ did not further activate the promoter activity, whereas a $\mathrm{Sp} 3$ induced the promoter activity $2.2(p<0.05)$ times when added together with Sp1 (Figure 2B).

These results indicate that both the $\mathrm{Sp} 1$ and $\mathrm{Sp} 3$ proteins are involved in the transcription of AKR1C3 gene, although the Sp3 seem to be the most important protein.

\section{STEROID AND PROMOTER ACTIVITY IN RELATION TO PROMOTER POLYMORPHISM}

When the HepG2 cells were exposed to high concentration $(25 \mu \mathrm{M})$ of DHT over night the promoter activity of the wildtype (A) construct increased 2.2-fold $(p=0.048)$, whereas for the polymorphic construct $(G)$ there were no significant induction observed (Figure 3A). When HepG2 cells were exposed to DHT a significant sevenfold increase of the AKR1C3 mRNA levels $(p=0.038)$ was found (Figure 3B).

\section{PROMOTER POLYMORPHISM AND PROSTATE CANCER RISK}

The distribution of the promoter polymorphism was in HardyWeinberg equilibrium. The allele frequency of the promoter polymorphism G in healthy participants were 39\% (Table 1), as in agreement with previous studies in Caucasians (Jakobsson et al., 2007). Individuals displaying an A-allele (A/G and A/A) showed 0.59 times decreased risk for prostate cancer compared to individuals homozygous for the G-allele (Table 2). The results were quit not significant $(p=0.058)$.

\section{DISCUSSION}

To evaluate the possible role for AKR1C3 in prostate cancer, a promoter polymorphism $(A>G$, rs3763676) were genotyped in a population based case-control study. The result indicates that the promoter SNP in the AKR1C3 gene may modulate the prostate cancer risk and that there may be an advantage to have an A-allele. The results are in agreement with our in vitro finding that the promoter activity of the wildtype A variant is induced by DHT and with our previous finding that the Gvariant displayed lower transcription activity in a prostate cancer cell line (Jakobsson et al., 2007). AKR1C3 is an important enzyme in the metabolism of DHT, particularly in the inactivation of DHT to the less potent androgen $3 \alpha$-Adiol (Lin et al., 1997). It is possible that A-carriers may have an improved protection against high concentrations of DHT since this allele is correlated with higher transcriptional activity, and is induced by DHT. Contradictory to this hypothesis, i.e., that high expression of AKR1C3 is protective against androgen load, is a study by Stanbrough et al. (2006) who found a 5.2-fold increase of AKR1C3 mRNA level in androgen-independent prostate cancer bone metastasis.

Recent studies have shown that another AKR1C3 polymorphisms (c90 G/A (rs7741), known to be in linkage disequilibrium with the $\mathrm{A}>\mathrm{G}$ promoter polymorphism $\left(R^{2}=1\right.$; International HapMap Consortium, 2005), is associated with prostate disease. The $\mathrm{c} 90 \mathrm{~A}$-allele has been associated with increased risk for prostate enlargement (Roberts et al., 2006), and increased risk of both familial and sporadic prostate cancer. (Cunningham et al., 2007). Additionally, another AKR1C3 SNP (rs4881400), not in linkage disequilibrium with the promoter polymorphism, has been associated with prostate cancer risk (Kwon et al., 2012). Thus it is likely that AKR1C3 play a role in the etiology of prostate related diseases. Whether the promoter polymorphism investigated in this study is associated with prostate cancer risk needs to be further investigated in larger prostate cancer case-control studies. The fact that the promoter SNP studied herein is included in common GWAS analysis such as Affymetrix SNP 6.0, will increase the chance to find such association.

In agreement with our results, one study found that the Gallele was significantly more frequent in women with PCOS. Like prostate cancer, PCOS is also considered to be an androgen dependent disease, and the authors speculated that the increased risk may be due to higher plasma testosterone levels in subjects homozygous for G-allele (Qin et al., 2006). However, a subsequent study were not able to find an association between the promoter $\mathrm{A}>\mathrm{G}$ polymorphism and PCOS (Goodarzi et al., 2008).

Here we show that DHT increase the promoter activity of the AKR1C3 promoter including the wildtype (A) sequence, whereas the polymorphic G-variant was not up-regulated in HepG2 cells. Moreover, the AKR1C3 mRNA level was induced sevenfold after DHT exposure in HepG2 cells. This finding was not in agreement with a study performed in LNCaP cells, where DHT was shown to decrease the expression of AKR1C3 by 70\% (Wang and Tuohimaa, 2007). This discrepancy of may be due to the different DHT concentrations used $(10 \mathrm{nM}$ versus $25 \mu \mathrm{M})$ in the studies. The former concentration is reflecting the physiological of DHT in the circulation, whereas the supra-physiologic concentration of $25 \mu \mathrm{M}$ reflects the high levels of DHT produced locally in the prostate (Olsson et al., 2011). Moreover, the androgen response may differ between the cell-lines used. Further investigations are 


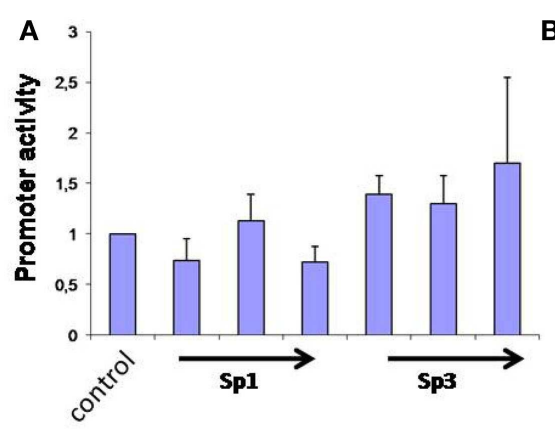

FIGURE 2 | (A) Transcriptional activities of the AKR1C3 promoter construct transiently transfected into DSL2 cells. The DSL2 cells were cotransfected with Sp-proteins in increasing concentrations. The bar graph represents mean \pm SD from at least three experiments. The luciferase expression was normalized to the transfection efficiency by $\beta$-galactosidase expression. Control background activity was increased twofold when $\operatorname{Sp} 3(0.5,1$, and $1.5 \mu \mathrm{g})$ were added to cells, whereas no significant affect was observed when increasing concentrations of Sp1 were added. (B) Human AKR1C3 promoter

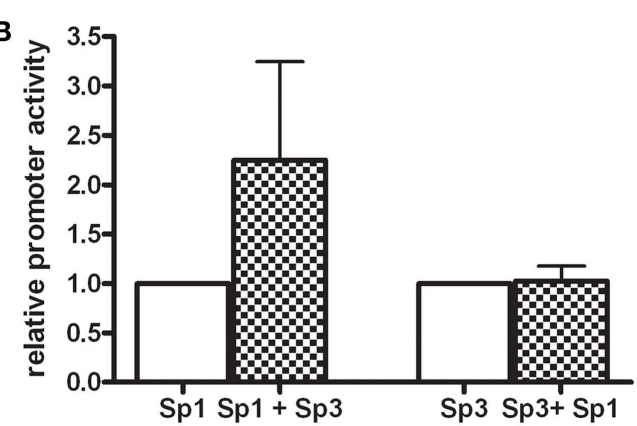

construct was transiently transfected into HepG2 cells cotransfected with Sp1/Sp3 proteins. The bar graph represents mean \pm SD from at least three experiments. The luciferase expression was normalized to the transfection efficiency by $\beta$-galactosidase expression. When the Sp1 protein $(1 \mu \mathrm{g})$ containing DSL cells were cotransfected with Sp3 $(1.5 \mu \mathrm{g})$ the promoter activity increased 2.2-fold. When the Sp3 $(1 \mu \mathrm{g})$ containing DSL cells were cotransfected with $\mathrm{Sp} 1(1.5 \mu \mathrm{g})$ no induction in promoter activity was observed.

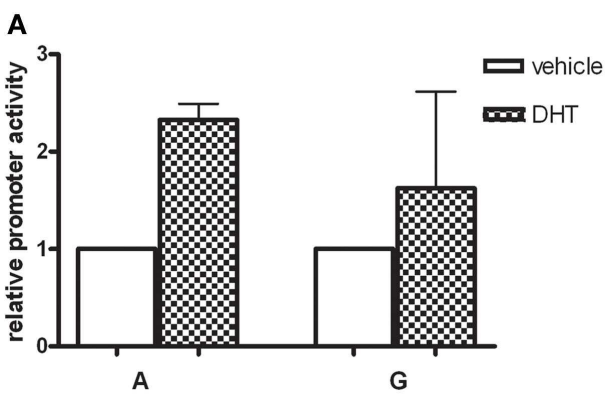

FIGURE 3 | (A) The HepG2 cells were transfected with the wildtype AKR1C3 promoter (A) and the polymorphic (G) construct and exposed to $25 \mu \mathrm{DHT}$ over night. The bar graph represents mean \pm SD from at least three experiments. The luciferase expression was normalized to the transfection efficiency by $\beta$-galactosidase expression. After DHT treatment and promoter activity of the wildtype $(A)$ significantly

Table 1 | Genotype and allele frequencies of the promoter polymorphism $(A>G)$ in a Swedish population sample of prostate cancer and controls.

\begin{tabular}{llc}
\hline & $\begin{array}{l}\text { Cases } \\
\%(\boldsymbol{n})\end{array}$ & $\begin{array}{l}\text { Controls } \\
\%(\boldsymbol{n})\end{array}$ \\
\hline AA genotype & $40(71)$ & $39(63)$ \\
GG genotype & $19(33)$ & $12(19)$ \\
AG genotype & $41(72)$ & $48(77)$ \\
\hline
\end{tabular}

required to evaluate how androgens modulate expression and activity of AKR1C3 in different cell types, particularly in androgen sensitive cells.

In order to study the cis-acting elements involved in the AKR1C3 basal promoter activity we transfected the promoter wildtype and two mutated (CCAAT- and GC-elements) promoter construct in HepG2 cells. The result indicates that the inverted
B

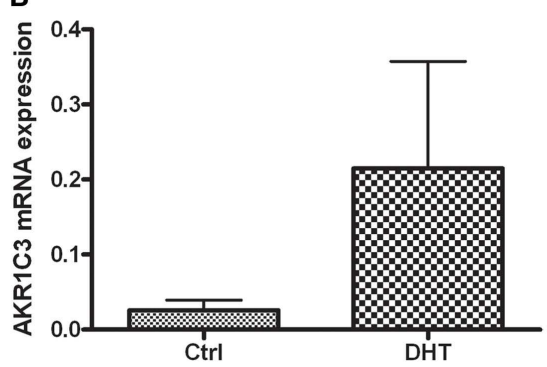

increased whereas no significant alteration was observed for the polymorphic (G) construct. (B) The mRNA expression of the human AKR1C3 gene in HepG2 cells was evaluated using real-time PCR. Significant increase in AKR1C3 mRNA levels was observed after incubation with $25 \mu \mathrm{M}$ DHT over night. The bar graph represents mean \pm SD from four experiments.

Table 2 | Prostate cancer risk estimates for AKR1C3 A/G promoter polymorphism among Swedish Caucasian men.

\begin{tabular}{lll}
\hline Genotype & Odds ratio & $\mathbf{9 5 \%} \mathbf{C l}$ \\
\hline$G / G$ & 1.00 & Ref. \\
A/G & 0.54 & $(0.28-1.03)$ \\
A/A & 0.65 & $(0.34-1.25)$ \\
$A^{*}$ & 0.59 & $(0.32-1.08)$
\end{tabular}

${ }^{*}$ All carriers of $A$ compared to homozygous carriers of $G$.

CCAAT-box is not involved in the basal transcription of AKR1C3. Instead binding to the CCAAT-box may have an inhibitory effect on the AKR1C3 expression since we observed an increase in promoter activity when this element was mutated. The GC-box on the other hand appears to be involved in the constitutive expression. The GC-boxes are GC rich sequences recognized by the Sp transcription factor family (Kingsley and Winoto, 1992). To 
further examine the trans-acting proteins involved in the AKR1C3 transcription, the wildtype promoter construct was transfected into DSL2 cells. DSL2 cells are used to specifically study the Sp family of transcription factors since these cells lack Sp-proteins. When constructs were added to the cells without the $\mathrm{Sp} 1 / \mathrm{Sp} 3$ expression vectors, a low background activity was observed. The addition of Sp3 increased the expression, whereas the addition of Sp1 alone did not induce the promoter activity. Co-transfection with Sp1 and $\mathrm{Sp} 3$ proteins also indicate that $\mathrm{Sp} 3$ may have a more impact on the promoter activity compared to Sp1.

Previous studies of the AKR1C3 promoter have shown that a 169-bp region $(-104$ to +65$)$ is capable of directing transcriptional activity (Ciaccio et al., 1996). This $5^{\prime}$-flanking region

\section{REFERENCES}

Bogason, A., Masquelier, M., Lafolie, P., Skogastierna, C., Paul, C., Gruber, A., and Vitols, S. (2011). Daunorubicin metabolism in leukemic cells isolated from patients with acute myeloid leukemia. Drug Metab. Lett. 4, 228-232.

Ciaccio, P. J., Walsh, E. S., and Tew, K. D. (1996). Promoter analysis of a human dihydrodiol dehydrogenase. Biochem. Biophys. Res. Commun. 228, 524-529.

Cunningham, J. M., Hebbring, S. J., Mcdonnell, S. K., Cicek, M. S., Christensen, G. B., Wang, L., Jacobsen, S. J., Cerhan, J. R., Blute, M. L., Schaid, D. J., and Thibodeau, S. N. (2007). Evaluation of genetic variations in the androgen and estrogen metabolic pathways as risk factors for sporadic and familial prostate cancer. Cancer Epidemiol. Biomarkers Prev. 16, 969-978.

Figueroa, J. D., Malats, N., GarciaClosas, M., Real, F. X., Silverman, D., Kogevinas, M., Chanock, S., Welch, R., Dosemeci, M., Lan, Q., Tardon, A., Serra, C., Carrato, A., GarciaClosas, R., Castano-Vinyals, G., and Rothman, N. (2008). Bladder cancer risk and genetic variation in AKR1C3 and other metabolizing genes. Carcinogenesis 29, 1955-1962.

Fung, K. M., Samara, E. N., Wong, C., Metwalli, A., Krlin, R., Bane, B., Liu, C. Z., Yang, J. T., Pitha, J. V., Culkin, D. J., Kropp, B. P., Penning, T. M., and Lin, H. K. (2006). Increased expression of type 23 alpha-hydroxysteroid dehydrogenase/type 5 17beta-hydroxysteroid dehydrogenase (AKR1C3) and its relationship with androgen receptor in prostate carcinoma. Endocr. Relat. Cancer 13, 169-180.

Goodarzi, M. O., Jones, M. R., Antoine, H. J., Pall, M., Chen, Y. D., and Azziz, R. (2008). Nonreplication of the type
5 17beta-hydroxysteroid dehydrogenase gene association with polycystic ovary syndrome. J. Clin. Endocrinol. Metab. 93, 300-303.

International HapMap Consortium. (2005). A haplotype map of the human genome. Nature 437, 1299-1320.

Jakobsson, J., Palonek, E., Lorentzon, M., Ohlsson, C., Rane, A., and Ekstrom, L. (2007). A novel polymorphism in the 17betahydroxysteroid dehydrogenase type 5 (aldo-keto reductase 1C3) gene testosterone levels in caucasian men. Pharmacogenomics J. 7, 282-289.

Jez, J. M., Flynn, T. G., and Penning, T. M. (1997). A new nomenclature for the aldo-keto reductase superfamily. Biochem. Pharmacol. 54, 639-647.

Kingsley, C., and Winoto, A. (1992). Cloning of GT box-binding proteins: a novel Sp1 multigene family regulating $\mathrm{T}$-cell receptor gene expression. Mol. Cell. Biol. 12, 4251-4261.

Kwon, E. M., Holt, S. K., Fu, R., Kolb, S., Williams, G., Stanford, J. L., and Ostrander, E. A. (2012). Androgen metabolism and JAK/STAT pathway genes and prostate cancer risk. Cancer Epidemiol. 36, 347-353.

Lin, H. K., Jez, J. M., Schlegel, B. P., Peehl, D. M., Pachter, J. A., and Penning, T. M. (1997). Expression and characterization of recombinant type 23 alpha-hydroxysteroid dehydrogenase (HSD) from human prostate: demonstration of bifunctional 3 alpha/17 beta-HSD activity and cellular distribution. Mol. Endocrinol. 11, 1971-1984.

Matsuura, K., Shiraishi, H., Hara, A., M., and Sakai, S. (1998). Identification of a principal mRNA species for human 3alpha-hydroxysteroid is associated with lower serum Sato, K., Deyashiki, Y., Ninomiya,

contains a CCT repeat element, 2 GC-boxes and a reverse CCAATbox. Qin and Rosenfield (2005) showed that the binding of Sp1/Sp3 to the CCT repeat element was important for the constitutive and forskolin stimulated AKR1C3 promoter activity in H295R cells. The GC- and CCAAT-boxes generally work as promoter signals in many eukaryotic cells. The GC-boxes are GC rich sequences recognized by the Sp transcription factor family (Kingsley and Winoto, 1992). Our results together with Qins (Qin and Rosenfield, 2005) clearly show that the transcription of AKR1C3 gene is driven by Sp-proteins.

In conclusion, our results further support previous findings that AKR1C3 play an important role in the androgen metabolism and in the etiology of prostate cancer.

dehydrogenase isoform (AKR1C3) that exhibits high prostaglandin D2 11-ketoreductase activity. $J$. Biochem. 124, 940-946.

Nakamura, Y., Suzuki, T., Nakabayashi, M., Endoh, M., Sakamoto, K. Mikami, Y., Moriya, T., Ito, A., Takahashi, S., Yamada, S., Arai, Y., and Sasano, H. (2005). In situ androgen producing enzymes in human prostate cancer. Endocr. Relat. Cancer 12, 101-107.

Olsson, M., Ekstrom, L., Guillemette, C., Belanger, A., Rane, A., and Gustafsson, O. (2011). Correlation between circulatory, local prostatic, and intra-prostatic androgen levels. Prostate 71, 909-914.

Palackal, N. T., Lee, S. H., Harvey, R. G., Blair, I. A., and Penning, T. M. (2002). Activation of polycyclic aromatic hydrocarbon trans-dihydrodiol proximate carcinogens by human aldo-keto reductase (AKR1C) enzymes and their functional overexpression in human lung carcinoma (A549) cells. J. Biol. Chem. 277, 24799-24808.

Penning, T. M., Burczynski, M. E., Jez, J. M., Hung, C. F., Lin, H. K., Ma, H., Moore, M., Palackal, N., and Ratnam, K. (2000). Human 3alpha-hydroxysteroid dehydrogenase isoforms (AKR1C1-AKR1C4) of the aldo-keto reductase superfamily: functional plasticity and tissue distribution reveals roles in the inactivation and formation of male and female sex hormones. Biochem. J. 351, 67-77.

Qin, K., Ehrmann, D. A., Cox, N. Refetoff, S., and Rosenfield, R. L. (2006). Identification of a functional polymorphism of the human type 5 17beta-hydroxysteroid dehydrogenase gene associated with polycystic ovary syndrome. J. Clin. Endocrinol. Metab. 91, 270-276.
Qin, K., and Rosenfield, R. L. (2005) Characterization of the basal promoter element of the human type 5 17beta-hydroxysteroid dehydrogenase gene. Biochim. Biophys. Acto 1728, 115-125.

Roberts, R. O., Bergstralh, E. J., Farmer, S. A., Jacobson, D. J., Hebbring, S. J., Cunningham, J. M., Thibodeau, S. N., Lieber, M. M., and Jacobsen, S. J. (2006). Polymorphisms in genes involved in sex hormone metabolism may increase risk of benign prostatic hyperplasia. Prostate 66, 392-404.

Söderström, T. G., Wadelius, M., Andersson, S., Johansson, J., Johansson, S., Granath, F., and Rane, A. (2002). 5-alpha reductase 2 polymorphisms as risk factors in prostate cancer. Pharmacogenetics 12, 307-312.

Stanbrough, M., Bubley, G. J., Ross, K., Golub, T. R., Rubin, M. A., Penning, T. M., Febbo, P. G., and Balk, S. P. (2006). Increased expression of genes converting adrenal androgens to testosterone in androgenindependent prostate cancer. Cancer Res. 66, 2815-2825.

Steckelbroeck, S., Jin, Y., Gopishetty, S., Oyesanmi, B., and Penning, T. M. (2004). Human cytosolic 3alpha-hydroxysteroid dehydrogenases of the aldo-keto reductase superfamily display significant 3beta-hydroxysteroid dehydrogenase activity: implications for steroid hormone metabolism and action. J. Biol. Chem. 279, 10784-10795.

Thigpen, A. E., Silver, R. I., Guileyardo, J. M., Casey, M. L., Mcconnell, J. D. and Russell, D. W. (1993). Tissue distribution and ontogeny of steroid 5 alpha-reductase isozyme expression. J. Clin. Invest. 92, 903-910.

Wadelius, M., Andersson, A. O., Johansson, J. E., Wadelius, C., and Rane, E. (1999). Prostate cancer associated 
with CYP17 genotype. Pharmacogenetics 9, 635-639.

Wang, J. H., and Tuohimaa, P. (2007). Regulation of 17betahydroxysteroid dehydrogenase type 2, type 4 and type 5 by calcitriol, LXR agonist and 5alphadihydrotestosterone in human prostate cancer cells. J. Steroid Biochem. Mol. Biol. 107, 100-105.
Conflict of Interest Statement: The authors declare that the research was conducted in the absence of any commercial or financial relationships that could be construed as a potential conflict of interest.

Received: 15 May 2012; accepted: 17 July 2012; published online: 06 August 2012.
Citation: Schulze JJ, Karypidis $H$ and Ekström L (2012) Basal and regulatory promoter studies of the AKR1C3 gene in relation to prostate cancer. Front. Pharmacol. 3:151. doi: 10.3389/fphar.2012.00151

This article was submitted to Frontiers in Experimental Pharmacology and Drug Discovery, a specialty of Frontiers in Pharmacology.
Copyright $\odot 2012$ Schulze, Karypidis and Ekström. This is an open-access article distributed under the terms of the Creative Commons Attribution License, which permits use, distribution and reproduction in other forums, provided the original authors and source are credited and subject to any copyright notices concerning any third-party graphics etc. 